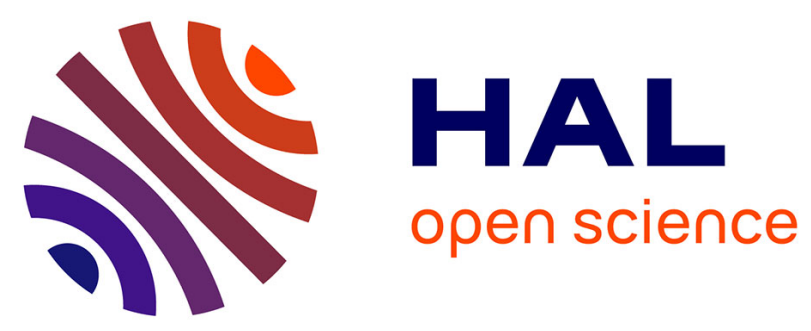

\title{
Cerebrovascular events in Takayasu arteritis: a multicenter case-controlled study
}

Priscille Couture, Thibaud Chazal, Charlotte Rosso, Julien Haroche, Anne Léger, Baptiste Hervier, Sandrine Deltour, Zahir Amoura, Fleur Cohen Aubart

\section{- To cite this version:}

Priscille Couture, Thibaud Chazal, Charlotte Rosso, Julien Haroche, Anne Léger, et al.. Cerebrovascular events in Takayasu arteritis: a multicenter case-controlled study. Journal of Neurology, 2018, 265 (4), pp.757 - 763. 10.1007/s00415-018-8744-8 . hal-01787078

\section{HAL Id: hal-01787078 \\ https://hal.sorbonne-universite.fr/hal-01787078}

Submitted on 7 May 2018

HAL is a multi-disciplinary open access archive for the deposit and dissemination of scientific research documents, whether they are published or not. The documents may come from teaching and research institutions in France or abroad, or from public or private research centers.
L'archive ouverte pluridisciplinaire HAL, est destinée au dépôt et à la diffusion de documents scientifiques de niveau recherche, publiés ou non, émanant des établissements d'enseignement et de recherche français ou étrangers, des laboratoires publics ou privés. 


\section{Cerebrovascular events in Takayasu arteritis: a multicenter case-controlled study}

Running title: Stroke in Takayasu arteritis

Priscille Couture $^{1}, \mathrm{MD}$, Thibaud Chazal ${ }^{1}, \mathrm{MD}$, Charlotte Rosso ${ }^{2,3}, \mathrm{MD}, \mathrm{PhD}$, Julien Haroche ${ }^{1,3}, \mathrm{MD}$, PhD, Anne Léger ${ }^{2}, M D$, Baptiste Hervier ${ }^{4}, M D, P h D$, Sandrine Deltour ${ }^{2}, M D$, Zahir Amoura ${ }^{1,3}, M D$, MSc and Fleur Cohen Aubart ${ }^{1,3}, \mathrm{MD}, \mathrm{PhD}$

(1) Assistance Publique-Hôpitaux de Paris, Hôpital de la Pitié-Salpêtrière, Service de Médecine 2, Institut e3m, Centre National de Référence Maladies Systémiques Rares, Lupus systémique et Syndrome des Anticorps Antiphospholipides, F-75013, Paris, France

(2) Assistance Publique-Hôpitaux de Paris, Hôpital de la Pitié-Salpêtrière, Service de Neurologie vasculaire, F-75013, Paris, France

(3) Université Paris VI Pierre et Marie Curie, Sorbonnes Universités, F-75013, Paris, France

(4) Assistance Publique-Hôpitaux de Paris, Hôpital de la Pitié-Salpêtrière, Département d'immunologie clinique, F-75013, Paris, France

Correspondence to Dr. Fleur COHEN-AUBART, Service de Médecine Interne 2, Institut e3m, Hôpital de la Pitié-Salpêtrière, 47-83 Boulevard de l'hôpital, 75651 PARIS CEDEX 13, France Email fleur.cohen@aphp.fr

Phone +33142178242

Fax +33142165804

Word count in full text: 2118

Character count in title including spaces: 82

Number of tables: 2

Number of figures: 0

Number of references: 49 
Key words: Takayasu arteritis, stroke, carotid artery, surgery

\section{Highlights}

Takayasu arteritis is a rare cause of stroke, especially in young adults.

Stroke in Takayasu arteritis may occur after carotid artery surgery.

Stroke is a major cause of disability in Takayasu arteritis.

The authors declare no conflicts of interest and no disclosures relevant to the manuscript.

This work was not supported by any funding.

All the authors (PC, TC, CR, JH, AL, BH, ZA and FCA) contributed to drafting/revising the manuscript for content and study design as well as analysis and interpretation of the data.

TC, PC, CR, BH, and FCA contributed to the acquisition of data.

PC and FCA conducted the statistical analysis.

ZA and FCA coordinated the study.

All the authors approved the final submitted version. 


\section{Abstract}

Objectives: Takayasu arteritis (TA) is a giant cells arteritis usually affecting young women and characterized by inflammatory and ischemic signs of large vessel involvement, including extracranial cerebral arteries. The impact of stroke on TA prognosis has not been well evaluated. Methods: We performed a retrospective multicenter review of patients with definite TA who experienced at least one stroke and compared the findings to 17 matched patients with TA diagnosis without neurological involvement.

Results: Seventeen patients (15 women, median age at stroke diagnosis 44 years) receiving a diagnosis of TA and stroke between 2002 and 2016 in our institution were included, from a cohort of 126 patients suffering from TA (13.5\%). At diagnosis, patients from both groups had comparable cardiovascular risk factors. The first cerebrovascular event was ischemic stroke $(n=15)$ or transient ischemic attack $(n=2)$. In 8 patients, stroke occurred after the TA diagnosis was made. In 4 patients, stroke occurred after carotid surgery. At the end of follow-up, $59 \%$ of patients had a neurological impairment, $35 \%$ had a recurrence of stroke, and $24 \%$ suffered from epilepsy. Conclusions: Stroke is a major cause of disability in TA patients. Internal carotid surgery may be performed with caution because of the risk of stroke after the procedure.

Abstract word count 212 
Table 1. Demographic, clinical, and biological presentation and imaging data of cases and controls.

\begin{tabular}{|c|c|c|}
\hline & $\begin{array}{l}\text { Patients with TA and } \\
\text { stroke } \\
(\mathrm{N}=17)\end{array}$ & $\begin{array}{l}\text { Controls (TA without } \\
\text { stroke) } \\
(\mathrm{N}=17)\end{array}$ \\
\hline Median age at diagnosis (years [range]) & $45[15-70]$ & $39[15-65]$ \\
\hline Median age at first stroke (years) & 44 & - \\
\hline Male/Female & $2 / 15$ & $2 / 15$ \\
\hline Median follow up (month [range])* & $137[27-294]$ & $73[17-417]$ \\
\hline \multicolumn{3}{|l|}{ Cardiovascular disease risk factors } \\
\hline - Smoking (median pack-years [range]) & $7[0-40]$ & $5[0-40]$ \\
\hline - Dyslipidemia & $4(23.5 \%)$ & $4(23.5 \%)$ \\
\hline - Hypertension & $8(47.0 \%)$ & $6(35.3 \%)$ \\
\hline - Diabetes mellitus & $2(11.8 \%)$ & $3(17.7 \%)$ \\
\hline - Coronaropathy & $1(5.9 \%)$ & $1(5.9 \%)$ \\
\hline - $\quad$ BMI (median [range]) & $25[14.8-30.2]$ & $23,3[14.8-32.7]$ \\
\hline - Familial history of MI or stroke & $1(5.9 \%)$ & $1(5.9 \%)$ \\
\hline - Peripheral artery disease & $1(5.9 \%)$ & 0 \\
\hline \multicolumn{3}{|l|}{ Symptoms at diagnosis } \\
\hline - Upper limb claudication & $4(23.5 \%)$ & $6(35.3 \%)$ \\
\hline - Lower limb claudication & $4(23.5 \%)$ & $1(5.9 \%)$ \\
\hline - Difference in SBP between arms > $10 \mathrm{mmHg}$ & $11(64.7 \%)$ & $12(70.6 \%)$ \\
\hline - Painful carotid & $2(11.8 \%)$ & $4(23.5 \%)$ \\
\hline - Decreased brachial artery pulse & $9(53.0 \%)$ & $10(58.8 \%)$ \\
\hline - Bruit over subclavian or carotid arteries & $12(70.6 \%)$ & $14(82.4 \%)$ \\
\hline - Bruit over femoral arteries & $2(11.8 \%)$ & $3(17.7 \%)$ \\
\hline - Cardiac murmur & $6(35.3 \%)$ & $5(29.4 \%)$ \\
\hline - Fever & $1(5.9 \%)$ & $4(23.5 \%)$ \\
\hline - Loss of weight & $2(11.8 \%)$ & $4(23.5 \%)$ \\
\hline \multicolumn{3}{|l|}{ Laboratory tests at diagnosis } \\
\hline - Median ESR (mm/h [range]) & 50 [4-100] & $27,5[5-52]$ \\
\hline - Median CRP (mg/L [range]) & $40[4-93]$ & $6[2-180]$ \\
\hline \multicolumn{3}{|l|}{ Imaging data at diagnosis } \\
\hline - Internal carotid stenosis* & $13(76.5 \%)$ & $4(23.5 \%)$ \\
\hline - Vertebral arteries stenosis & $5(29.4 \%)$ & $5(29.4 \%)$ \\
\hline - External carotid stenosis & $4(23.5 \%)$ & $4(23.5 \%)$ \\
\hline - Subclavian arteries stenosis & $15(88.2 \%)$ & $12(70.6 \%)$ \\
\hline - Aortic aneurysm & $5(29.4 \%)$ & $4(23.5 \%)$ \\
\hline - Renal arteries stenosis & $6(35.3 \%)$ & $6(35.3 \%)$ \\
\hline - Visceral arteries stenosis & $6(35.3 \%)$ & $7(41.2 \%)$ \\
\hline Death & $2(11.8 \%)$ & $1(5.9 \%)$ \\
\hline Median survival (month, [range]) & $41[2-229]$ & $73[17-417]$ \\
\hline Carotid surgery & $6(35.3 \%)$ & $2(11.8 \%)$ \\
\hline Surgical re-intervention on carotid & $3(17.7 \%)$ & 0 \\
\hline
\end{tabular}

TA: Takayasu arteritis; BMI: body mass index; MI: myocardial infarction; SBP: systolic blood pressure; ESR: erythrocyte sedimentation rate; CRP: C-reactive protein; ${ }^{*} p<0,05$. 
Table 2. Characteristics of stroke in Takayasu arteritis patients.

Stroke features

Patients with stroke

$\mathbf{N}=17$

\begin{tabular}{|c|c|c|}
\hline \multicolumn{3}{|c|}{ Symptoms } \\
\hline- & Headache & 4 \\
\hline- & Aphasia & 5 \\
\hline- & Hemiparesis & 10 \\
\hline- & Cerebellar ataxia & 1 \\
\hline- & Visual loss & 4 \\
\hline- & Diplopia & 3 \\
\hline \multicolumn{2}{|c|}{ Transient ischemic attack } & 2 \\
\hline \multicolumn{2}{|c|}{ Ischemic stroke } & 15 \\
\hline \multicolumn{2}{|c|}{ NIHSS at admission (mean [range]) } & $4[0-18]$ \\
\hline \multicolumn{2}{|c|}{ Stroke after surgery } & 4 \\
\hline \multicolumn{2}{|c|}{ Co-occurrence of stroke and TA diagnosis } & 4 \\
\hline \multicolumn{2}{|c|}{ Diagnosis of TA before stroke } & 8 \\
\hline \multicolumn{2}{|c|}{ Diagnosis of stroke before TA } & 5 \\
\hline \multicolumn{3}{|c|}{ Involved territory } \\
\hline- & Anterior cerebral artery & 4 \\
\hline- & Middle cerebral artery & 12 \\
\hline- & Posterior cerebral artery & 0 \\
\hline- & Cerebellar artery & 1 \\
\hline \multicolumn{2}{|c|}{ Multiple infarcts } & 3 \\
\hline \multicolumn{3}{|c|}{ Treatment before stroke } \\
\hline- & Corticosteroids & 5 \\
\hline- & Statin & 5 \\
\hline- & Antiplatelet therapy & 9 \\
\hline- & Immunosuppressor & 2 \\
\hline \multicolumn{3}{|c|}{ Treatment after stroke } \\
\hline- & Thrombolytic therapy & 3 \\
\hline- & Antiplatelet therapy & 17 \\
\hline- & Anticoagulant & 3 \\
\hline- & Statin & 13 \\
\hline \multirow[t]{3}{*}{-} & Corticosteroids & 17 \\
\hline & Median dose $(\mathrm{mg})$ & 30 \\
\hline & High dose intravenous steroid therapy & 6 \\
\hline- & Methotrexate & 7 \\
\hline- & Tocilizumab & 2 \\
\hline \multicolumn{3}{|c|}{ Outcomes } \\
\hline- & Neurological impairment & 10 \\
\hline- & Stroke recurrence: one relapse & 4 \\
\hline- & Stroke recurrence: two relapses or more & 2 \\
\hline- & Epilepsy & 4 \\
\hline- & Cognitive impairment & 1 \\
\hline- & Final Barthel score (median [range]) & 85 [70-100] \\
\hline- & Median final CRP (mg/L [range]) & $5[0-18]$ \\
\hline \multicolumn{2}{|c|}{ Median time between two strokes (range) } & $10[2-25]$ \\
\hline
\end{tabular}

NIHSS: National Institute of Health Stroke Scale; TA: Takayasu arteritis; CRP: C-reactive protein. 
Takayasu arteritis (TA) is a giant cells arteritis usually affecting young women and characterized by inflammatory and ischemic signs of large vessel involvement. The aorta and its large arterial branches are typically involved in TA and may lead to coronary artery disease, renovascular hypertension, intestinal ischemia and/or stroke [33]. Vascular involvement is usually associated with an inflammatory state with an increased erythrocyte sedimentation rate (ESR) and/or Creactive protein (CRP). Internal carotid artery (ICA) involvement is uncommon, and intracranial arteries are exceptionally affected $[2,6]$. The occurrence of strokes during TA is estimated to be between 10 and $20 \%$, and a more recent meta-analysis found a prevalence of $15.8 \%[11,36]$. However, the impact of stroke on prognosis in TA patients has not been well evaluated. We thus conducted a retrospective, case-controlled study with an updated review of the literature, to evaluate the prognosis of cerebrovascular events in TA and to characterize the clinical and imaging presentation.

\section{Patients and Methods}

\section{Patients' selection}

We performed a retrospective study in the Departments of Internal Medicine and Neurology of a French University hospital. Patients who received a definite diagnosis of TA according to the American college of rheumatology criteria [3] and who experienced a cerebrovascular event were identified through the computerized local database (Programme de Médicalisation des Systèmes d'Information, PMSI). Only patients in whom the cerebrovascular event occurred at diagnosis or during the evolution of TA were included. For patients in whom TA diagnosis was made after stroke occurrence, 2 independent medical doctors reviewed the medical records, and the patients were finally included if the stroke was obviously related to the TA. All forms of cerebrovascular events were considered, including transient ischemic attacks (TIA), hemorrhagic and ischemic strokes. Cerebrovascular events related to atrial fibrillation or overt atherosclerotic lesions were 
excluded.

The control group patients were also identified through the PMSI, and medical records were obtained to confirm the absence of neurological signs. These patients had also received a definite TA diagnosis and were sex-matched in a 1:1 ratio with patients of the group "cerebrovascular event".

\section{Data collection}

The characteristics of all patients were obtained through medical records. A standardized form was used to collect data for all cases, including demographics (age and sex), date of TA diagnosis and cerebrovascular event, and cardiovascular risk factors (smoking, diabetes mellitus, hypertension, hypercholesterolemia and family history). Clinical data (headache, visual impairment, upper and lower limb claudication, asymmetric blood pressure, painful carotid, vascular murmur and fever), biological data at diagnosis of TA (ESR, CRP, fibrinogen, gammaglutamyl transferase (GGT) hemoglobin and platelet count) and imaging studies (magnetic resonance imaging (MRI), ${ }^{18}$ fluorodesoxyglucose $\left({ }^{18} \mathrm{FDG}\right)$ positron emission tomography (PET)scan if available) were collected for all patients as well as treatments received at diagnosis of TA and at the time of the first cerebrovascular event.

All stroke characteristics were recorded, including clinical features and cerebral MRI findings.

\section{Statistical analyses}

Data are presented as median (range) for continuous variables and number (\%) for qualitative variables. Differences between groups were tested using the Mann-Whitney test for continuous data and Fisher exact test for qualitative data. All tests were two-sided, and a p-value $<0.05$ was considered statistically significant. The statistical analyses were performed using commercially available software (IBM SPSS for Windows).

\section{Results}




\section{Patients' characteristics at TA diagnosis}

Seventeen patients who received a diagnosis of TA and stroke between 2002 and 2016 in our institution were included, from a cohort of 126 patients suffering from TA (13.5\%). We enrolled 17 controls with TA who were sex matched and had no neurological signs. There were 15 women (88\%) and 2 men (12\%) in each group. The median duration of follow-up was 137 months (27 $294)$ in the stroke group and 73 months (17-417) in the control group.

The baseline characteristics of the patients are detailed in Table 1.

At diagnosis, patients from both groups had comparable cardiovascular risk factors. There were no significant differences in terms of smoking, diabetes mellitus, peripheral artery disease, body mass index (BMI), coronaropathy or familial history of cardiovascular and cerebrovascular event frequencies. Hypertension was more frequently observed in the stroke group (47 versus 35\%) compared to the controls, although this difference was not statistically significant.

The clinical presentation of TA at diagnosis was similar in the 2 groups.

The median blood CRP level at TA diagnosis was higher in patients with cerebrovascular events than in control patients ( 40 and $6 \mathrm{mg} / \mathrm{L}$ respectively), but the difference was not statistically significant. Other biological markers of inflammation at TA diagnosis, namely, ESR, hemoglobin and fibrinogen levels, were similar in the two groups.

Interestingly, imaging data revealed more ICA stenosis in patients with stroke than in controls $(76,5 \%$ versus $23,5 \% ; p=0.005)$. The other vascular territories were similarly involved in the 2 groups.

\section{Characteristics of the cerebrovascular events and outcomes}

The characteristics of the cerebrovascular events are detailed in the Table $\mathbf{2}$.

The first cerebrovascular event was ischemic stroke $(n=15)$ or TIA $(n=2)$. There were no hemorrhagic strokes. Stroke occurred with a typical presentation: hemiparesis in $53 \%$ of patients, 
aphasia in $29 \%$, visual impairment in $24 \%$ and cerebellar ataxia in $6 \%$. The median National Institutes of Health Stroke scale score (NIHSS) on admission was 4 (ranging from 0 to 18). Most cerebrovascular events were located in the ICA, especially in the middle cerebral artery

(MCA) territory $(n=12,71 \%)$ and the anterior cerebral artery (ACA) territory $(n=4,24 \%)$, whereas one event (6\%) was located in the cerebellar artery territory, and none were in the posterior cerebral artery territory. Three patients (18\%) had multiple infarcts, mostly in the same vascular territory, which was the carotid territory in all cases of multiples strokes.

Cerebrovascular events occurred in 8 patients suffering from previously diagnosed TA with a median delay of 13 years (ranging from 1 to 21 ) after TA diagnosis. In 4 patients, stroke occurred after carotid surgery. Stroke was the first symptom of TA in 9 patients $(53 \%)$. The TA diagnosis was confirmed with a median duration of 2 years (ranging from 0 to 12 years). In 4 cases, stroke and TA were concomitantly diagnosed.

All strokes were considered linked to the disease because of high CRP levels, suggestive imaging results, and exclusion of cardioembolic or atherosclerotic causes.

It is worth noting, that at the end of follow-up 59\% of the patients had a neurological impairment, $35 \%$ had a recurrence of stroke and $24 \%$ suffered from epilepsy. These neurological sequelae had an impact on the patients' autonomy since the median final Barthel score was still below 100 at the end of follow-up. Two patients died, and the median survival rate was 41 months.

\section{Discussion}

Stroke is an important feature of TA, occurring in at least $15.8 \%$ of cases $[11,32,44]$. It has a variable presentation $[5,6,29-31,38]$. Stroke or TIA may be the first sign of the disease, in a variable percentage ranging from $9 \%$ to $93 \%[17,25,37,42,46,47]$. We found that cerebrovascular events revealed TA in $53 \%$ of cases. Among these cases, the diagnosis of TA was 
confirmed with a median delay of 2 years, which may have resulted in delayed treatment of the arteritis. Interestingly, we found that stroke occurred after carotid surgery in 4 cases.

\section{Mechanisms of stroke in TA}

The underlying mechanisms of ischemic strokes in TA remain unclear. Various mechanisms have been described: vascular occlusion secondary to arterial thrombosis and vasculitis [11, 22, 35], carotid aneurysm [7], embolism from aortic regurgitation, hemodynamic origin due to tight stenosis or vascular steal [24], vasospasm in hypertensive encephalopathy [8] or rarely, carotid artery dissection [14], distal carotid stump embolism [20] or moyamoya disease [43]. In our series, patients with stroke had significantly more ICA stenosis than controls. Almost all patients had a stroke in ACA or MCA territories, and only 3 strokes were in border-zones, whereas the others were large lobar infarctions. Contrast-enhanced ultrasonography may help to detect active vascular inflammation in TA [15]. In a recent American study including 79 patients, $11.4 \%$ patients presented with acute ischemic stroke: $6.3 \%$ with TIA and $1.3 \%$ with symptomatic intracranial hemorrhage [6]. Vascular imaging showed that $22.8 \%$ of patients had narrowing of the ICA; the right ICA was affected more often than the left, and all patients with ICA involvement also had common carotid artery stenosis. The authors hypothesize that ICA stenosis in TA could be secondary to inflammatory vasculitis more than the result of prior embolization, because 6 patients had multifocal stenosis, suggestive of a vasculitis etiology. In contrast, Kumral et al. found that $25 \%$ of patients with ischemic stroke presented with micro-embolus during transcranial doppler sonography monitoring, suggesting an embolic mechanism in the pathogenesis of stroke in TA [26].

A recent study found that lupus anticoagulant or a diagnosis of antiphospholipid syndrome were found in $45 \%$ of TA patients in a retrospective cohort of 22 patients; lupus anticoagulant was associated with a higher prevalence of cerebrovascular events [19]. In our cohort, 2 patients had an antiphospholipid biology and one immunoglobulin IgM anticardiolipin antibodies without 
criteria for an antiphospholipid syndrome. No patients in the control group had antiphospholipid or anticardiolipin antibodies. The number of patients is too small to make a conclusion regarding the impact of antiphospholipids antibodies on cerebrovascular risk. Other hypercoagulability states have also been associated with stroke in TA [40].

\section{Stroke and cardiovascular risk in TA}

Concerning risk factors of stroke in TA, a French retrospective study revealed that Maghreb patients had significantly more stroke than European patients [4]. The geographical origin did not differ in our series between the 2 groups. Ringleb et al. also suggested that TA presented with similar cerebrovascular signs in Europe and Japan [39]. Women may have more neurological involvement since female patients with TA have more frequent involvement of the thoracic aorta and its branches, whereas involvement of the abdominal aorta and its branches is more common in males [27]. Since the number of cases of stroke in TA is low, it is difficult to make a conclusion regarding female predominance.

A previous study showed that anemia and low body mass index (BMI) were associated with increased cardiovascular disease in patients with TA [28]. Our study did not find the same results, since BMI and hemoglobin were not different in the "stroke" and the "control" groups. Lastly, as in our series, a Korean study found that the conventional stroke risk factors, ESR and CRP, did not differ significantly between the stroke and control groups [18].

In a Chinese study, neurological features in patients with TA were variable and correlated with the number of arteries and the site of involvement. Resistant hypertension was one of the most important risk factors for hemorrhagic stroke in patients with TA [48]. We also observed more hypertension in the "stroke" group, although the difference was not statistically significant.

\section{Treatments and outcomes}


Treatments in TA usually include low-dose aspirin, anti-inflammatory medications (corticosteroids, frequently associated with immunosuppressive drugs). Recently, biologics in TA have been increasingly used [1, 9], especially in cases of stroke [34]. In our series, 2 patients received tocilizumab, whereas 7 received methotrexate. Stroke may also occur during infliximab treatment [21]. Due to the rarity of TA-associated strokes, it is difficult to give evidence-based recommendations on the use of biologics in this setting.

Our patients had neurological sequelae in $59 \%$ of cases. Paula et al. found the same important morbidity: 12 of 18 (66.7\%) patients developed neurological impairments [10]. In this study, one patient died as a result of cerebral hyperperfusion after carotid surgery. In our series, $24 \%$ of strokes occurred after vascular surgery, and 35\% of patients required a carotid revascularization, sometimes twice. Fields et al. reported that operated patients with active TA were more likely to develop thrombosis or restenosis [12]. Thus, we recommend that surgical interventions may be achieved when the disease is quiescent $[13,41]$. Stent placement may also be used [16], although intra stent thrombosis may occur [45], possibly due to increased inflammation of the arterial wall.

\section{Limitations}

Our study has several limitations: it is a retrospective study with memory bias. The patients were likely to suffer from a more severe disease spectrum since they were treated in a tertiary care center. In addition, finally, imaging analysis was not uniformly performed because vascular involvement was investigated with different types of vascular imaging studies (CT-scan, MRI or sonography), each with its own limitations $[23,49]$.

\section{Conclusions}

The occurrence of stroke during TA may be the first sign of the disease or may occur during followup, especially after vascular surgery. Stroke is associated with high morbidity since $60 \%$ of patients sustain neurological impairment, and recurrence occurs in $35 \%$ of cases. This is the major finding 
of this study which shows that stroke occurrence in TA impact the outcomes and in particular neutrological disability. The occurrence of stroke during TA is associated with the presence of ICA stenosis. A systematic evaluation of intracranial vascularization should be performed in this setting. 


\section{References}

1. Abisror N, Mekinian A, Lavigne C, Vandenhende MA, Soussan M, Fain O, Club Rhumatismes et I, Snfmi (2013) Tocilizumab in refractory Takayasu arteritis: a case series and updated literature review. Autoimmun Rev 12:1143-1149

2. Alibaz-Oner F, Direskeneli H (2015) Update on Takayasu's arteritis. Presse Med 44:e259-265

3. Arend WP, Michel BA, Bloch DA, Hunder GG, Calabrese LH, Edworthy SM, Fauci AS, Leavitt RY, Lie JT, Lightfoot RW, Jr., et al. (1990) The American College of Rheumatology 1990 criteria for the classification of Takayasu arteritis. Arthritis and rheumatism 33:1129-1134

4. Arnaud L, Haroche J, Limal N, Toledano D, Gambotti L, Costedoat Chalumeau N, Le Thi Huong Boutin D, Cacoub P, Cluzel P, Koskas F, Kieffer E, Piette JC, Amoura Z (2010) Takayasu arteritis in France: a singlecenter retrospective study of 82 cases comparing white, North African, and black patients. Medicine 89:1-17

5. Bejot Y, Couvreur G, Ricolfi F, Osseby GV, Cochet A, Giroud M (2011) Acute cerebrovascular manifestation of Takayasu arteritis. Am J Med 124:e5-6

6. Bond KM, Nasr D, Lehman V, Lanzino G, Cloft HJ, Brinjikji W (2017) Intracranial and Extracranial Neurovascular Manifestations of Takayasu Arteritis. AJNR Am J Neuroradiol 38:766-772

7. Caballero PE (2011) Common carotid artery aneurysm revealing Takayasu's arteritis. Journal of stroke and cerebrovascular diseases : the official journal of National Stroke Association 20:556-558

8. Camara-Lemarroy CR, Lara-Campos JG, Perez-Contreras E, Rodriguez-Gutierrez R, Galarza-Delgado DA (2013) Takayasu's arteritis and posterior reversible encephalopathy syndrome: a case-based review. Clinical rheumatology 32:409-415

9. Comarmond C, Plaisier E, Dahan K, Mirault T, Emmerich J, Amoura Z, Cacoub P, Saadoun D (2012) Anti TNF-alpha in refractory Takayasu's arteritis: cases series and review of the literature. Autoimmun Rev 11:678684

10. de Paula LE, Alverne AR, Shinjo SK (2013) Clinical and vascular features of Takayasu arteritis at the time of ischemic stroke. Acta Reumatol Port 38:248-251

11. Duarte MM, Geraldes R, Sousa R, Alarcao J, Costa J (2016) Stroke and Transient Ischemic Attack in Takayasu's Arteritis: A Systematic Review and Meta-analysis. Journal of stroke and cerebrovascular diseases : the official journal of National Stroke Association 25:781-791

12. Fields CE, Bower TC, Cooper LT, Hoskin T, Noel AA, Panneton JM, Sullivan TM, Gloviczki P, Cherry KJ, Jr. (2006) Takayasu's arteritis: operative results and influence of disease activity. J Vasc Surg 43:64-71

13. Ham SW, Kumar SR, Rowe VL, Weaver FA (2011) Disease progression after initial surgical intervention for Takayasu arteritis. J Vasc Surg 54:1345-1351

14. Hao R, Zhang J, Ma Z, Xiao M, Zhou L, Kang N, Liang X, Li F (2016) Takayasu's arteritis presenting with common carotid artery dissection: A rare case report. Exp Ther Med 12:4061-4063

15. Herlin B, Baud JM, Chadenat ML, Pico F (2015) Contrast-enhanced ultrasonography in Takayasu arteritis: watching and monitoring the arterial inflammation. BMJ Case Rep 2015

16. Hu J, Huang H, Zhang X, Li G, Liu Q, Wu M, Li G, Chen K, Shi S (2012) Stent placement for treatment of long segment $(>/=80 \mathrm{~mm}$ ) carotid artery stenosis in patients with Takayasu disease. J Vasc Interv Radiol 23:1473-1477

17. Humayun MA, Masood A, Waseem T, Ahmad F, Raza T (2014) An unusual cause of stroke in a young female. Am J Emerg Med 32:685 e683-685

18. Hwang J, Kim SJ, Bang OY, Chung CS, Lee KH, Kim DK, Kim GM (2012) Ischemic stroke in Takayasu's arteritis: lesion patterns and possible mechanisms. J Clin Neurol 8:109-115

19. Jordan NP, Bezanahary H, D'Cruz DP (2015) Increased risk of vascular complications in Takayasu's arteritis patients with positive lupus anticoagulant. Scand J Rheumatol 44:211-214

20. Kato Y, Dembo T, Takeda H, Fukuoka T, Nagoya H, Deguchi I, Maruyama H, Furuya D, Tanahashi N (2010) Stroke as a manifestation of Takayasu's arteritis likely due to distal carotid stump embolism. Intern Med 49:695-699

21. Katoh N, Kubota M, Shimojima Y, Ishii W, Matsuda M, Akamatsu T, Ikeda S (2010) Takayasu's arteritis in a patient with Crohn's disease: an unexpected association during infliximab therapy. Intern Med 49:179-182

22. Kawano H, Toyoda K, Otsubo R, Hishikawa T, Minematsu K (2009) Tortuous carotid artery lumens in Takayasu's arteritis. Journal of stroke and cerebrovascular diseases : the official journal of National Stroke Association 18:403-404

23. Keenan NG, Mason JC, Maceira A, Assomull R, O'Hanlon R, Chan C, Roughton M, Andrews J, Gatehouse PD, Firmin DN, Pennell DJ (2009) Integrated cardiac and vascular assessment in Takayasu arteritis by cardiovascular magnetic resonance. Arthritis and rheumatism 60:3501-3509

24. Kim HJ, Suh DC, Kim JK, Kim SJ, Lee JH, Choi CG, Yoo B, Kwon SU, Kim JS (2005) Correlation of neurological manifestations of Takayasu's arteritis with cerebral angiographic findings. Clin Imaging 29:79-85

25. Kumar VS, Dutt S, Bhat R (2014) Takayasu's arteritis--stroke as an initial presentation. J Assoc Physicians India 62:623-627

26. Kumral E, Evyapan D, Aksu K, Keser G, Kabasakal Y, Balkir K (2002) Microembolus detection in patients 
with Takayasu's arteritis. Stroke 33:712-716

27. Lim AY, Lee GY, Jang SY, Gwag HB, Choi SH, Jeon ES, Cha HS, Sung K, Kim YW, Kim SM, Choe YH, Kim DK (2015) Gender differences in clinical and angiographic findings of patients with Takayasu arteritis. Clinical and experimental rheumatology 33:S-132-137

28. Liu Q, Dang A, Lv N, Wang X, Zheng D (2016) Anaemia and low body mass index are associated with increased cardiovascular disease in patients with Takayasu arteritis. Clinical and experimental rheumatology 34:S16-20

29. Maeda Y, Taguchi H, Kudo T, Okano Y (2016) Takayasu arteritis and ischaemic stroke. QJM 109:45-46

30. Makin K, Isbel M, Nossent J (2017) Frequency, presentation, and outcome of Takayasu arteritis in Western Australia. Mod Rheumatol:1-5

31. Monti L, Servillo R, Grazzini I, Khader L, Acampa M, Cerase A (2017) Neuroimaging of Takayasu Arteritis in a Patient with Ulcerative Rectocolitis. Journal of stroke and cerebrovascular diseases : the official journal of National Stroke Association 26:e129-e132

32. Mustafa KN, Hadidy A, Sweiss NJ (2010) Clinical and radiological features of Takayasu's arteritis patients in Jordan. Rheumatol Int 30:1449-1453

33. Numano F, Okawara M, Inomata H, Kobayashi Y (2000) Takayasu's arteritis. Lancet 356:1023-1025

34. Osman M, Emery D, Yacyshyn E (2015) Tocilizumab for Treating Takayasu's Arteritis and Associated Stroke: A Case Series and Updated Review of the Literature. Journal of stroke and cerebrovascular diseases : the official journal of National Stroke Association 24:1291-1298

35. Park KC, Kim JH, Yoon SS, Heo SH (2008) Takayasu's disease presenting with atherothrombotic ischaemic stroke. Neurol Sci 29:363-366

36. Park MC, Lee SW, Park YB, Chung NS, Lee SK (2005) Clinical characteristics and outcomes of Takayasu's arteritis: analysis of 108 patients using standardized criteria for diagnosis, activity assessment, and angiographic classification. Scand J Rheumatol 34:284-292

37. Pereira VC, de Freitas CC, Luvizutto GJ, Sobreira ML, Peixoto DE, Magalhaes Ido N, Bazan R, Braga GP (2014) Stroke as the First Clinical Manifestation of Takayasu's Arteritis. Case Rep Neurol 6:271-274

38. Pfefferkorn T, Bitterling H, Hufner K, Opherk C, Schewe S, Pfister HW, Straube A, Dichgans M (2008) Malignant hemispheric infarction in Takayasu arteritis. J Neurol 255:1425-1426

39. Ringleb PA, Strittmatter EI, Loewer M, Hartmann M, Fiebach JB, Lichy C, Weber R, Jacobi C, Amendt K, Schwaninger M (2005) Cerebrovascular manifestations of Takayasu arteritis in Europe. Rheumatology 44:1012-1015

40. Rustagi T, Majumder S (2011) Crohn's-Takayasu's arteritis overlap with hypercoagulability: an optimal milieu for ischemic stroke. J Dig Dis 12:142-146

41. Saadoun D, Lambert M, Mirault T, Resche-Rigon M, Koskas F, Cluzel P, Mignot C, Schoindre Y, Chiche L, Hatron PY, Emmerich J, Cacoub P (2012) Retrospective analysis of surgery versus endovascular intervention in Takayasu arteritis: a multicenter experience. Circulation 125:813-819

42. Sharma BK, Jain S (1998) A possible role of sex in determining distribution of lesions in Takayasu Arteritis. Int J Cardiol 66 Suppl 1:S81-84

43. Skeik N, Rumery KK, Udayakumar PD, Crandall BM, Warrington KJ, Sullivan TM (2013) Concurrent Takayasu arteritis with common variable immunodeficiency and moyamoya disease. Ann Vasc Surg 27:240 e213-248

44. Soto ME, Espinola N, Flores-Suarez LF, Reyes PA (2008) Takayasu arteritis: clinical features in 110 Mexican Mestizo patients and cardiovascular impact on survival and prognosis. Clinical and experimental rheumatology 26:S9-15

45. Srinivas BC, Patra S, Reddy B, Nagesh CM, Manjunath CN (2013) Reocclusion and stroke due to immediate plaque protrusion following endovascular treatment of carotid artery successfully treated with intra-arterial urokinase and stent in stent in a patient with Takayasu arteritis with severe disease of all arch vessels. Cardiovasc Interv Ther 28:394-397

46. Vanoli M, Daina E, Salvarani C, Sabbadini MG, Rossi C, Bacchiani G, Schieppati A, Baldissera E, Bertolini G, Itaka Study G (2005) Takayasu's arteritis: A study of 104 Italian patients. Arthritis and rheumatism 53:100107

47. Wheeler G, Kropf J, Jeanmonod R (2012) Vasculitis presenting with myocardial infarction, stroke, and aortitis in a middle-aged man. J Emerg Med 43:655-658

48. Yang L, Zhang H, Jiang X, Song L, Qin F, Zou Y, Wu H, Bian J, Zhou X, Hui R, Zheng D (2015) Clinical Features and Outcomes of Takayasu Arteritis with Neurological Symptoms in China: A Retrospective Study. The Journal of rheumatology 42:1846-1852

49. Zhu FP, Luo S, Wang ZJ, Jin ZY, Zhang LJ, Lu GM (2012) Takayasu arteritis: imaging spectrum at multidetector CT angiography. Br J Radiol 85:e1282-1292 